\title{
OBITUARY
}

\section{Dr Albert Tricot}

Spinal Cord (2011) 49, 3; doi:10.1038/sc.2010.108

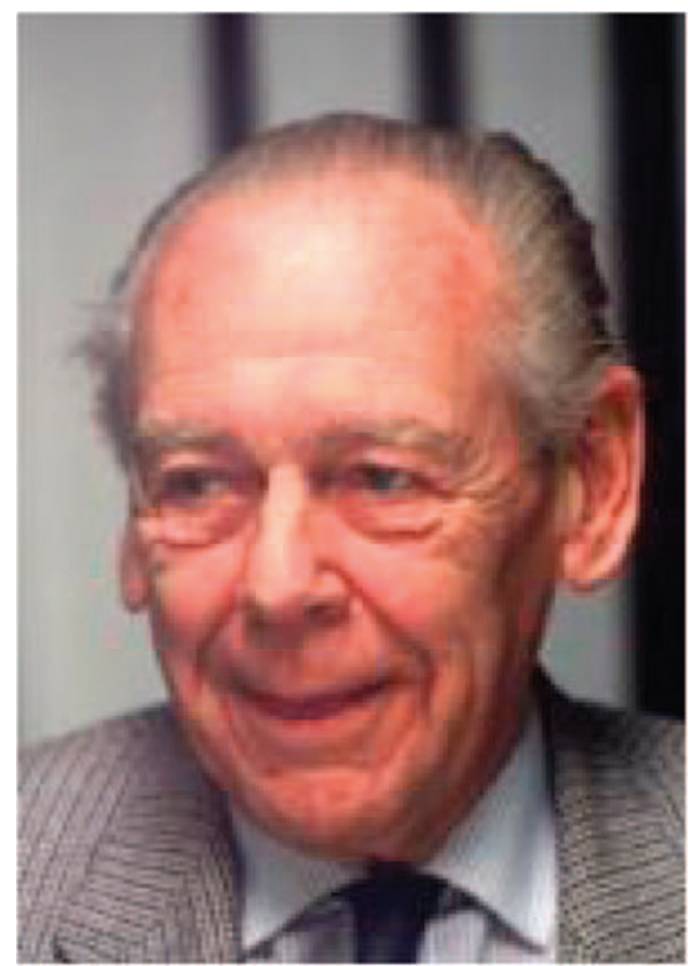

Chevalier Dr Albert Tricot died in Brussels on 11 May 2010. He was a well-known important personality in rehabilitation with special interest in sports for disabled.

After graduating at the Universite Libre de Bruxelles as medical doctor in 1946, he became an assistant in the Surgical Department of University Hospital Brugmann in Bruxelles in 1947. He was active in further developments of prosthesis and orthesis. In 1949, Prof Pierre Houssa asked him to help start up the rehabilitation Centre (CTR). In close contact with Sir Ludwig Guttmann he combined sports and rehabilitation, with special emphasis on arching. He accompanied the Belgian team for the first participation in the International Games at Stoke Mandeville. The creation of the Sports Association of CTR followed.

In 1961, Chevalier Tricot was at the side of Guttmann when the IMSOP was founded. The following year he was at the creation of the European Federation of Physical Medicine and Readaptation, of which he became Director general in 1965.

He was IMSOP president from 1973 to 1977.

From 1975 to 1985 he was medical director of CTR. His list of further important positions includes presidency of AFIGAP, member of Conseil d'Administration of the Interfederal Olympic Committee, president of Van Goethem Brichant foundation.

His efforts were honored with the title Officer in the Order of Leopold 1, Commander in The order of the Crown, Knight in the Ordre du Mérite de la République Italienne. He was ennobled by the King in 1990. His coat of arms of knight contains wheels and the devise 'Fortitudo et Voluntas'.

I have known him as a nice and friendly person, always caring for those near to him, his patients and the athletes. For junior doctors, as myself at that time, he was encouraging and he opened doors in the central organs for initiatives of juniors such as us. At the annual IMSOP meetings he was the dean of our Belgian group, and the meetings over dinner we had with him were warm and welcoming. He was a great and gentle man.

J-J Wyndaele and A Parent University Antwerp, Universitair Ziekenhuis Antwerpen, Edegem/Antwerp, Belgium E-mail: Jean-Jacques.Wyndaele@uza.be 